\title{
Comparative Evaluation of the Bond Strength of Different Base Metal Alloys With Porcelain-An Invitro Study
}

\author{
"Dr. Rajesh, ${ }^{*}$ Dr. Sandhya M Raghavan, ${ }^{* *}$ Dr. T. Sreelal, \\ Dr. Digesh Balachandran \\ "Assistant Professor Department of Prosthodontics, Govt. Dental College, Kottayam, Kerala, India. \\ **: Professor \& Head of Department Department of Prosthodontics, SreeMookambika Institute of Dental \\ Sciences, Kulasekaram, Tamilnadu, India. \\ **:Assistant Professor Department of Pedodontics\& Preventive Dentistry, Govt. Dental College, Kottayam, \\ Kerala, India. \\ *Corresponding author: Dr. Rajesh C
}

\begin{abstract}
:
Aim: To evaluate and compare the porcelain bond strength of Nickel-Chromium and Cobalt-Chromium alloys. Materials and Methods: The alloy systems used in the study were one proprietary brand each of nickelchromium and cobalt-chromium alloy type-Commend- and Lithecast respectively. For the porcelain bond strength study, five test specimens were made each with Commend and Lithecast. The Vintage porcelain system was employed for the porcelain application. The specimens were tested on Instron testing machine.

Results: Student't' test revealed no significant difference in the porcelain bond strength between nickelchromium and cobalt-chromium alloys- Commend and Lithecast respectively.

Conclusion: Within the limitations of the study, no significant difference was noted between nickel- chromium and cobalt-chromium alloy with respect to the bond strength with porcelain. Hence taking into consideration the economic effectiveness of nickel-chromium alloys, they can be used as the core material for metal-ceramic restorations in place of cobalt-chromium alloys except in nickel-allergic patients.
\end{abstract}

Keywords: Porcelain-bond strength, nickel-chromium alloy, cobalt-chromium alloy, universal testing machine.

\section{Introduction:}

Ceramics play an inevitable role in prosthodontics in general, and fixed prosthodontics in particular ranging from single full veneer crowns to multiple implant-supported restorations. Their excellent biocompatibility, wear resistance, colour stability and translucency have made them the most reliable esthetic restorative material in the field of dentistry. Metal-ceramic system, which combines the strength and accuracy of cast metal with the esthetics of porcelain was developed to overcome the fracture potential of ceramics. Alloys those have proved most satisfactory for metal ceramic crowns and fixed partial dentures are gold-palladium alloy with small amounts of gallium, indium and tin. The high cost and incompatibility of gold alloys with certain types of porcelains led to the development of alloys containing little or no gold and thereby introduction of base metal alloys in the field of metal- ceramic restorations. They possess desirable properties such as low cost, increased strength and hardness, high fusion temperatures and greater resistance to distortion during porcelain firing. However, one inherent problem with the base metal alloys is their questionable biocompatibility, particularly with nickel containing alloys. Contact dermatitis from nickel containing prosthesis appears to be a risk to some patients. So also, beryllium which is added to control the oxide formation is carcinogenic in nature. ${ }^{1}$ To minimize these allergic responses, cobalt-chromium alloys can be used instead of nickel-chromium alloys. But they are difficult to cast even though they have better mechanical properties than nickel-chromium group.

The primary requirement for the success of metal-ceramic prosthesis is the development of a durable bond between the porcelain and the alloy. Once such a bond is achieved, there is an opportunity to introduce stresses in the prosthesis during the porcelain firing procedures. An unfavorable stress distribution during the cooling process can result in cracking of porcelain, and delayed fracture can also occur. For successful metalceramic prosthesis, both a strong interface bond and thermal compatibility are required. ${ }^{2}$

A variety of tests have been advocated for measuring the bond strength. None can be regarded as an exact measure of the adhesion of porcelain to metal except in cases in which the metal-porcelain couple is matched thermally so that porcelain adjacent to the interface is essentially stress-free. ${ }^{2}$ The present study was 
carried out to determine the efficacy among the base metal alloys in bonding with porcelain by comparing the shear bond strength of one brand each of nickel-chromium and cobalt-chromium alloy- (Commend and Lithecast respectively) with porcelain (Vintage Halo-Shofu)

Test Specimen For Porcelain-Metal Bond

\section{Methodology:}

The test specimen for the porcelain-metal bond consisted of two components

\section{TEST SPECIMEN}

\section{Component-1}

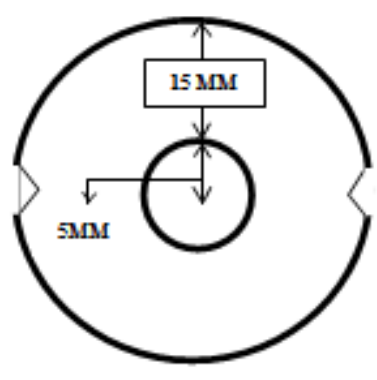

FRONTAL

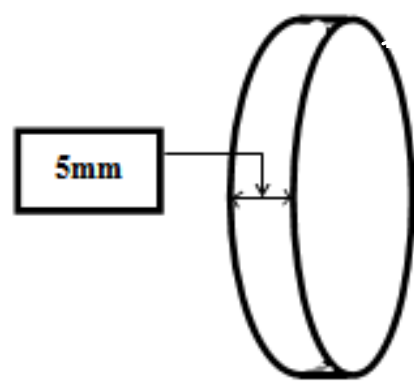

LATERAL

\section{Component-2}

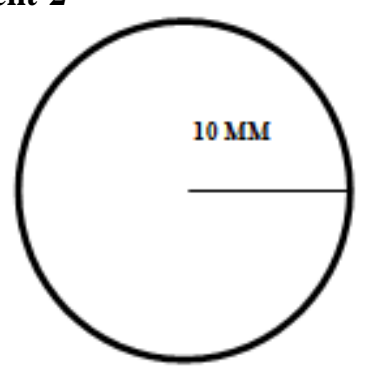

FRONTAL

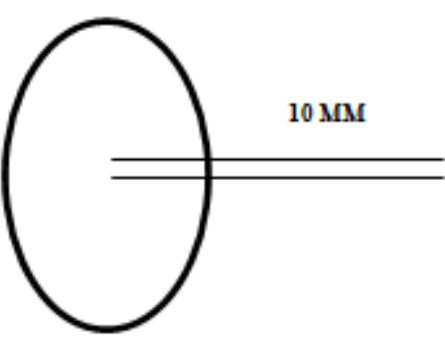

LATERAL

1) A circular metallic component containing a central hole; the external diameter of the component was $20 \mathrm{~mm}$, the diameter of the hole was $5 \mathrm{~mm}$ and the thickness was $5 \mathrm{~mm}$. The component contained two notches at the outer rim to accommodate the stainless steel wire to be utilized during the pull-test on the Universal Testing machine.

2) Another circular metallic component with a central stem of $10 \mathrm{~mm}$ length. The diameter of the circular part was half that of the first component ie. about $10 \mathrm{~mm}$.

The component parts of the test specimen were made of the corresponding metals for testing the porcelain-bond strength.

Group A- Five specimens of nickel-chromium (COMMEND)

Ruby Dental Products Inc. Japan

Group B - Five specimens of cobalt-chromium (LITHECAST)

American Dent. All. Inc. Glendale, California

The required number of wax patterns of the test specimen were made from the inlay wax - (Rolex Inlay Casting Wax, Normal Hard Type). 
Comparative Evaluation of the Bond Strength of Different Base Metal Alloys With Porcelain-An ....

\section{Investing}

Phosphate bonded investments not containing carbon - Wirovest investment powder (Bego, USA) and Begosol investment liquid (Bego, USA) was used for investing the wax pattern in a No. 9 casting ring. The powder: liquid ratio was according to the manufacturer's instructions. To obtain a bubble -free uniform mix, the investment was mixed with a vacuum mixer (Cuumyx Labo 14, Confident India) and poured into the casting ring on a vibrator.

\section{Burn-Out}

Before taking to the hot air oven for wax burn out, the casting ring with the invested pattern was setaside for 60 minutes for the proper hardening of the investment. The wax burn- out was done according to the instructions given by the manufacturer of each alloy. The burn- out began at the room temperature in the oven and the maximum temperature was as follows:

$\begin{array}{lll}\text { Group A } & - & 870^{\circ} \text { Celsius for } 60 \text { minutes } \\ \text { Group B } & - & 982^{\circ} \text { Celsius for } 60 \text { minutes }\end{array}$

Casting Procedure

After reaching the proper burn-out temperature in the oven and complete wax burn-out, the casting ring was taken from the oven and placed in the appropriate location in the already adjusted induction casting machine (Fornax, Bego, Germany). Proper amount of pellets of alloy were put into the crucible. The lid of the casting machine is closed, the induction was in on position and when the appropriate melting of the alloy is reached, as can be seen from the top glass portion, the centrifugation is started. The whole process took approximately three minutes.

\section{Retrieval of The casted Specimens}

When the centrifugation is completed, the molten casting ring is taken outside and after 60 minutes of cooling in the room temperature the casted specimens were retrieved with the sprues intact.

Individual test specimens were taken after cutting away the sprue in a high-speed lathe with No. 2507 cutting disc and were polished in a step- wise manner starting with 18- fluted carbide burs followed by fine and superfine diamond burs. (Figure: 1)

\section{Heat Treatment of The Test Specimens}

The heat treatment of 5 test specimens in each group involved six steps: degassing (once), opaquing (twice), body bake (twice) and glazing (once). The degassing step was completed according to the instructions of the manufacturer of each alloy. The four remaining steps were performed according to the recommended Vintage porcelain cycle (Table 1).

\section{Application of The Ceramic}

Before the application of the ceramic (Vintage Halo-Shofu), the two component parts of the test specimen was aligned in such a manner that the second component was positioned exactly in the middle of the first component with the notch in the latter seen clearly at the border.

Starting with the opaque ceramic, the powder and the liquid were mixed and placed through the central hole of the first component on to the circular part of the second component. It was applied to a total thickness of $0.2 \mathrm{~mm}$ and fired followed by sufficient body ceramic to each specimen to form a total ceramic thickness of $1 \mathrm{~mm}$ and subjected to firing in the ceramic furnace (Wizard-JELRUS INTERNATIONAL). (Figure: 2)

Ten specimens were made in this way: five each of Commend (Ni-Cr) and Lithecast(Co-Cr).

\section{Testing of the Specimen}

The metal-porcelain bond strength of each specimen was determined on a Universal testing machine (INSTRON CORPORATION). Each end of the test specimen was connected to a wedge action grip on the testing machine (Figure: 3 ). A tensile load was applied gradually by moving the cross head of the machine at a speed of $2.0 \mathrm{~mm} / \mathrm{min}$. Ultimately, debonding or the fracture of the test specimen occurred and the maximum load subjected was noted.

Data Analysis:

Student's 't' test was applied to compare the average porcelain bond strength. (Snedecor and Cochran, 1967). ${ }^{3}$

DOI: $10.9790 / 0853-1607010713 \quad$ www.iosrjournals.org $9 \mid$ Page


Table 2 : The porcelain - bond strength of $\mathrm{A}$

\section{Results:}

Table 3 : The porcelain bond strength of $\mathrm{B}$

The average bond strength of B was 0.416 while that A was 0.384 these difference is not real. But it may be attributed to a chance difference as indicated by the ' $t$ ' test of significance. $\left(t_{8}=0.63\right)$.

\section{Discussion:}

Metal-ceramic restoration has been recommended widely for single crowns, short-span bridges, longspan bridges and implants. The restoration has received wide acceptance and is the most widely used system in fixed Prosthodontics including implantology.

The Egyptian fiancés are the first known effort to enamel a substructure with a ceramic veneer. The technique metamorphosed through the works of Fonzi(fused porcelain to metal to produce terrometallic teeth 1806), development of porcelain fused to gold systems in 1956, development of porcelain fused to base metal systems in 1970 and the introduction of titanium as a coping and framework metal in early 90's. Since its introduction, the metal ceramic restoration has been called by various names at different times like Ceramco crown, porcelain fused to gold, porcelain veneer crown etc. but metal ceramic is a more precise term scientifically.

The metal ceramic restoration is composed of (1) a metal casting or coping which fits over the tooth preparation (2) a ceramic that is fused to the coping.

The metal ceramic restoration -MCR- combines the strength and the accuracy of cast metal with the esthetics of porcelain. But due to low ductility, the fracture of the porcelain or porcelain chipping is not a rare occurrence.

The alloys and the porcelain used in metal ceramic restorations should meet the following basic requirements: ${ }^{4}$

1. Closely matching coefficients of thermal contraction with a slight high value for the metal.

2. High proportional limit and the modulus of elasticity for the alloy.

3. High melting range for the alloy to prevent deformation during porcelain firing- Temperature resistance or sag resistance.

4. Good wetting of the metal or the metal oxide by the porcelain.

5. A soluble oxide layer in the porcelain.

6. No discoloration of porcelain by the surface oxide.

7. No undue reaction between the metal/ metal oxide and porcelain.

8. No toxic effects on the surrounding tissue by the metal- Biocompatibility.

9. The metal should be clinically acceptable with regard to castability, accuracy of fit and appearance.

10. The metal should exhibit minimal creep during the firing of the porcelain and possess adequate mechanical strength for multiple splinting and bridge work.

11. The casting should be fine grained to prevent high temperature fracture.

12. The metal should be readily post-soldered or pre-soldered.

One of the prime requirements for a ceramic metal system is a durable bond between the ceramic veneer and the metal coping. The most common mechanical failure of these restorations is the ceramic debonding from the metal. Generally, the bond is a result of chemisorption by diffusion between the surface oxides on the alloy and in the ceramic. The oxides are formed during the wetting of the alloy by the ceramic and firing of the ceramic during the degassing process. ${ }^{5}$

The compositions of the alloys in the present study were as follows:

A) Commend $77 \% \mathrm{Ni}, 14 \% \mathrm{Cr}, 4.7 \% \mathrm{Mo}, 2 \% \mathrm{Al}, 1.8 \% \mathrm{Be}, 0.5 \%$ other metals

B) Lithecast $63 \% \mathrm{Co}, 29 \% \mathrm{Cr}, 6 \% \mathrm{Mo}, 1 \% \mathrm{Mn}, 1 \% \mathrm{Si}$, less than $1 \%$ other metals

The analysis of the porcelain bond strength showed non-significant difference between A and B. This is in agreement with the earlier studies. ${ }^{6,7,12}$ In De Melo $R A$ et al's study, the shear bond strength between a porcelain system and four base metal alloys, two nickel-chromium and two cobalt-chromium were studied. There was no significant difference among the shear bond strength between the base metal alloys and the porcelain tested. ${ }^{7}$ This is consistent with an earlier study by Alfredo Julio Fernandez ${ }^{8}$ and a recent study by Vojdani $\mathrm{M}$ et $\mathrm{al}^{9}$. In the former study, the shear bond strength between three brands of porcelain to three brands of nickel-chromium and one experimental cobaltchromium-titanium alloy were evaluated. The cobalt-chromium-titanium alloy had the same bond strength as that of the 
nickel-chromium alloy. In his study, Vojdani et al compared the effect of thermal and mechanical cycling on bond strength of a ceramic to Nickel-chromium and cobalt-chromium alloys and concluded that the effect is the same for all tested porcelain-metal system.

Evaluation of the metal-ceramic bond is complicated by the lack of an accepted laboratory test with proven clinical significance. However these tests do make it clear that different base metal alloys vary widely in their abilities to bond to porcelain.

\section{Conclusion:}

A plethora of alloys are available in the market today for metal ceramic restorations. A number of factors have to weigh before selecting an alloy for good performance clinically. The most important of these factors are the cost of the metal and its mechanical properties. From the study it can be concluded that the cobalt-chromium alloy used in the study does not offer any advantage over the proprietary used nickelchromium alloys both in terms of cost and mechanical properties. Hence except in nickel sensitive patients, the nickel- chromium alloys can be used for metal ceramic restorations without any concern.

\section{Limitations of the study:-}

The porcelain-metal bond test used in the present study is one among the many tests used to determine the bond strength between the ceramic and the metal; however none of them can be called ideal. Hence, the data obtained from different tests are often not comparable. ${ }^{4}$ There is a need to include base metal alloys containing titanium in the future studies.

\section{Acknowledgement:}

To Mr K Sisupalan, Senior scientist and Engineer (Retd), Material Characterisation Division, VSSC, Thiruvananthapuram for the guidance given during scientific testing of material.

\section{Bibliography:}

[1]. Phillips' Science of Dental materials, First South Asia Edition Elsevier 132-3

[2]. Phillips' Science of Dental materials, Anusavice ,Eleventh Edition Elsevier 677-8

[3]. Snedecor, G.W and Cochran,W.G :Statistical methods, Sixth edition. The Iowa State College Press, Ames, Iowa. Oxford; I.B.H Pub. Co; New Delhi

[4]. Craig”s Restorative Dental Materials, $12^{\text {th }}$ Edition, Elsevier 466

[5]. Mackert JR Jr, Ringle RD, Parry EEet al: The relationship between oxide adherence and porcelain-metal bonding. J Dent Res $67: 474,1988$ :

[6]. Stannard JG ,Marks L , Kanchanatawewat K Effect of multiple firing on the bond strength of selected matched porcelain fused to metal combinations .J.Prosthet.Dent .1990 Jan ;63 (6) :627-9

[7]. De Melo RM ,Travassos AC, Neisser MP Shear bond strength of a ceramic system to alternative metal elements J.Prosthet.Dent ;2005 Jan ;93 (1):64-9

[8]. Alfredo Julio Fernandes Neto. Bond strength of three dental porcelains to Ni-Cr and Co-Cr-Ti alloys; Fraz. Dent. J. vol 17, no. 1, Ribeirao Preto 2006.

[9]. Vojdani M, Shaghaghian S, Khaledi A, Adibi S. The effect of thermal and mechanical cycling on bond strength of a ceramic to Ni-Cr and Co-Cr alloys; Indian J Dent Res 2012 Jul-Aug 23(4) 509-13

[10]. Johnson T, Noort RV ,Stokes CW Surface analysis of porcelain fused to metal system.Dent.Mater.2005;Aug 5 .

[11]. Harold F Morris Properties of cobalt-chromium metal ceramic alloys after heat treatment. J.Prosthet.Dent; 1990; 63:426-33

[12]. Phillips' Science of Dental Materials-Anusavice, Tenth Edition ; W.B Saunders Company; 452-3 
Tables:

Table (1): Vintage porcelain cycle

\begin{tabular}{|l|l|}
\hline First opaque & $650^{\circ} \mathrm{C}-950^{\circ} \mathrm{C}$ under vacuum at $60^{\circ} \mathrm{C}$ per minute. Release vacuum at $950^{\circ} \mathrm{C}$. Bench Cool \\
\hline Second opaque & $650^{\circ} \mathrm{C}-940^{\circ} \mathrm{C}$ under vacuum at $60^{\circ} \mathrm{C}$ per minute. Release vacuum at $940^{\circ} \mathrm{C}$. Bench Cool \\
\hline First body bake & $650^{\circ} \mathrm{C}-910^{\circ} \mathrm{C}$ under vacuum at $60^{\circ} \mathrm{C}$ per minute. Release vacuum at $910^{\circ} \mathrm{C}$. Bench Cool \\
\hline Second body bake & $650^{\circ} \mathrm{C}-905^{\circ} \mathrm{C}$ under vacuum at $60^{\circ} \mathrm{C}$ per minute. Release vacuum at $905^{\circ} \mathrm{C}$. Bench Cool \\
\hline Glaze & $650^{\circ} \mathrm{C}-900^{\circ} \mathrm{C}$ under air at $60^{\circ} \mathrm{C}$ per minute. Bench Cool \\
\hline
\end{tabular}

Table (2): The porcelain - bond strength of A

\begin{tabular}{|c|c|}
\hline Sl.No. & Bond Strength (Mpa) \\
\hline 1 & 0.39 \\
\hline 2 & 0.32 \\
\hline 3 & 0.42 \\
\hline 4 & 0.35 \\
\hline 5 & 0.44 \\
\hline
\end{tabular}

Mean $=0.384$

Table (3): The porcelain bond strength of B

\begin{tabular}{|c|c|}
\hline Sl.No. & Bond Strength (Mpa) \\
\hline 1 & 0.38 \\
\hline 2 & 0.42 \\
\hline 3 & 0.35 \\
\hline 4 & 0.45 \\
\hline 5 & 0.48 \\
\hline
\end{tabular}

Mean $=0.416$

\section{Figures:}

Figure (1): The Component parts of the test specimen for porcelain-bond strength

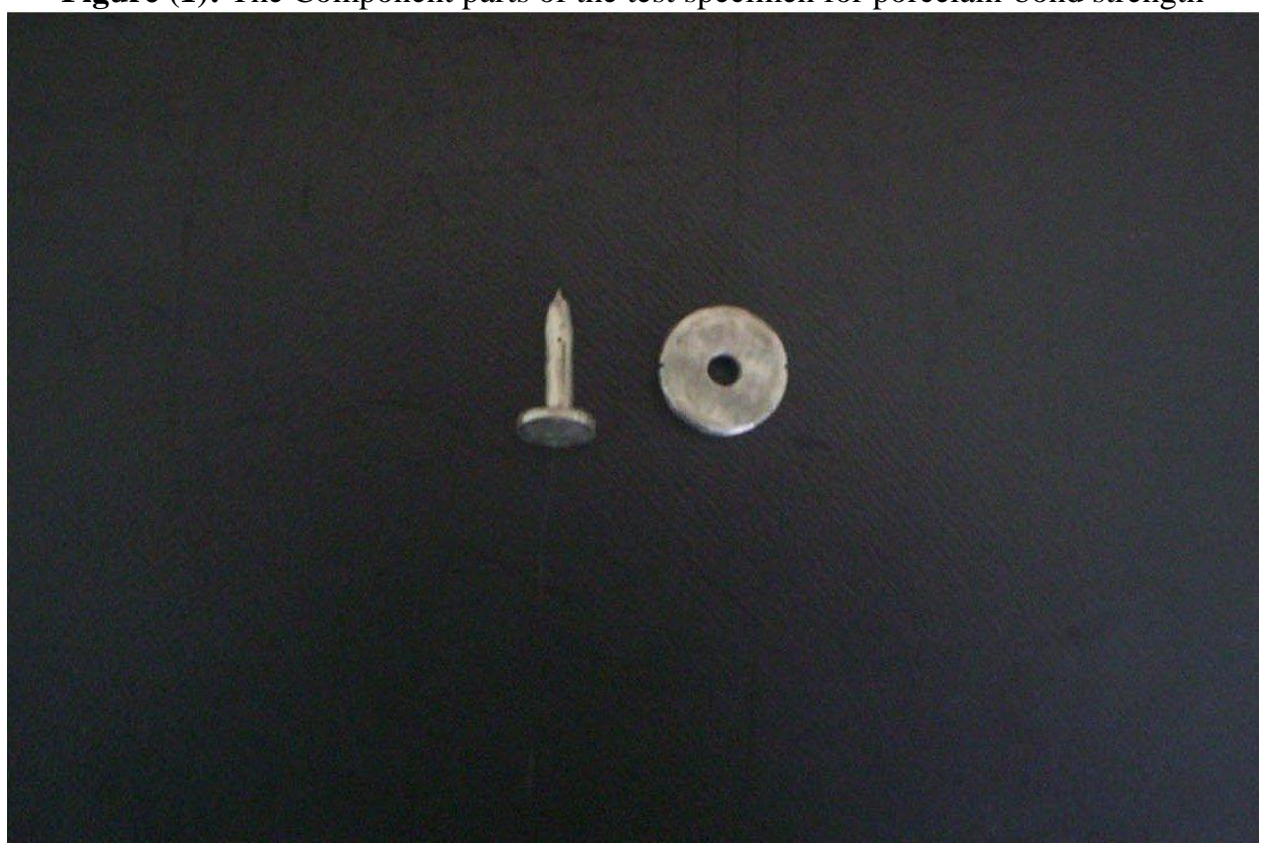


Figure (2): The Component parts joined with porcelain

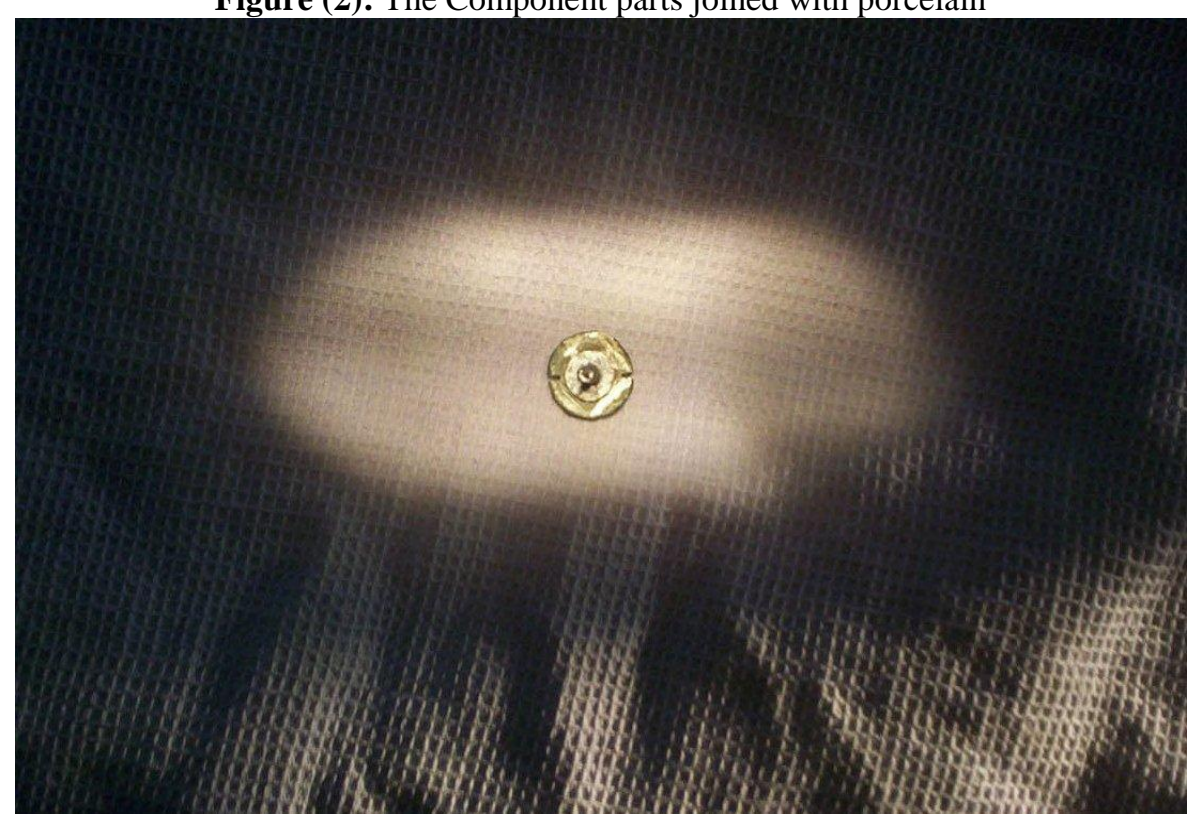

Figure (3): The test specimen in the Instron testing machine

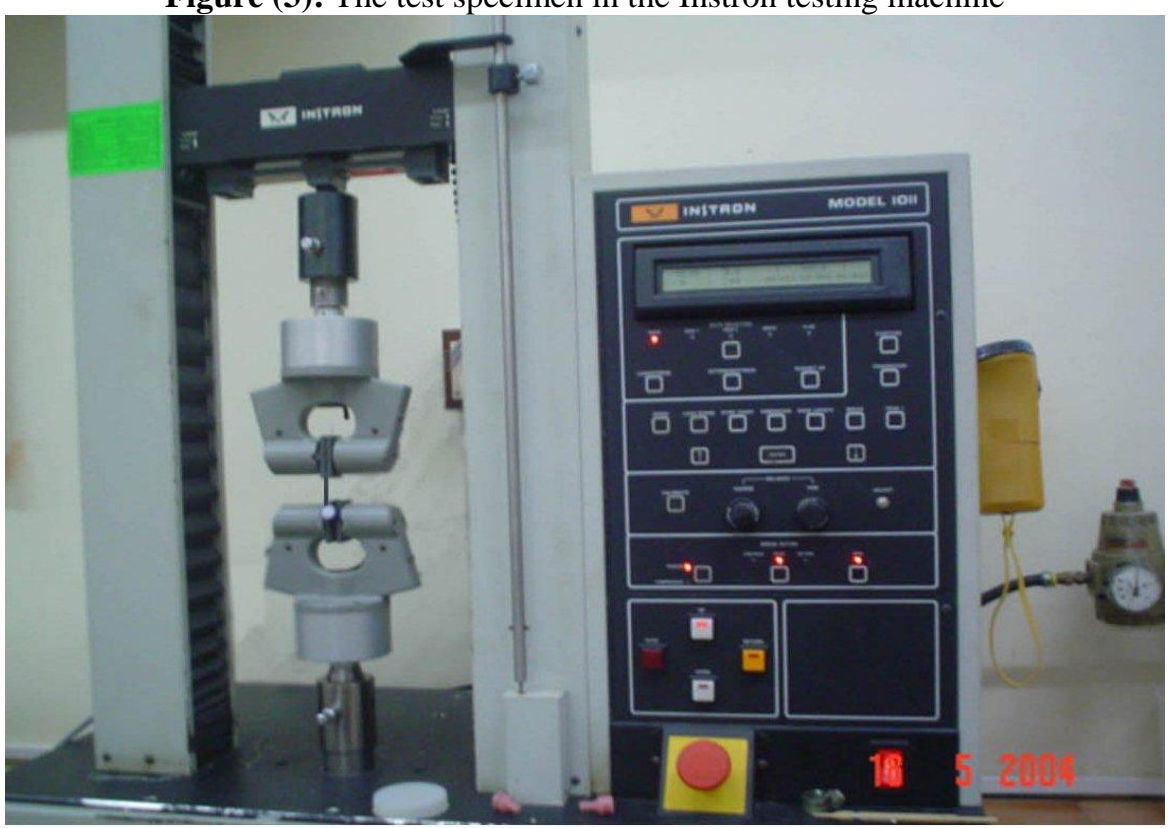

* Dr. Rajesh. "Comparative Evaluation of the Bond Strength of Different Base Metal Alloys With Porcelain-An Invitro Study." IOSR Journal of Dental and Medical Sciences (IOSR-JDMS) 16.7 (2017): 07-13. 